Pesquisa e Reflexão em Educação Básica

\title{
Estratégias de ensino aprendizagem para a inclusão de alunos público-alvo da educação especial na escola de ensino médio
}

Marcia Raika e Silva Lima ${ }^{1}$

\begin{abstract}
Resumo:
As discussões sobre a inclusão de alunos público-alvo da educação especial (PAEE) perpassa os diferentes setores da sociedade, em especial o meio acadêmico. Neste intento, esse relato de pesquisa trata-se de recorte da tese de doutorado que se realizou no ano de 2016, pela UFPI, e tem como objetivo geral: analisar as significações de professor do ensino médio acerca da inclusão de alunos público-alvo da educação especial-PAEE. Trata-se de uma pesquisa qualitativa, com abordagem na Psicologia Sócio-histórica. O método utilizado foi o Materialismo Histórico Dialético. Optou-se pela entrevista como instrumento metodológico para coleta e registro dos dados. Como base analítica, teve-se os Núcleos de Significação. O resultado evidenciou que a professora Vargas exalta a criatividade para driblar as contingências imperativas da sociedade, que desconsidera as particularidades dos alunos PAEE, e os meios de acesso e a permanência escolar. Concluímos que a professora Vargas, mediada pela vivência com esses alunos incluídos, transformou seu pensar, seu sentir e seu agir diante da educação inclusiva.
\end{abstract}

\section{Palavras-chave:}

Educação especial e inclusiva. Ensino médio. Alunos público-alvo da educação especial.

\section{Teaching-learning strategies for the inclusion of special educa- tion's target audience students in the high school}

\begin{abstract}
:
Discussions about the inclusion of students in the target public of special education-PAEE permeates the different sectors of society, especially the academic environment. In this attempt, this research report is an excerpt from the doctoral thesis that was carried out in 2016 , by UFPI, and its general objective: to analyze the meanings of a high school teacher about the inclusion of students target audience of special education-PAEE. It is a qualitative research, with an approach in Socio-historical Psychology. The method used was Dialectical Historical Materialism. The interview was chosen as
\end{abstract}

1 Doutora em Educação. Universidade Estadual do Maranhão - Campus Caxias. E-mail: marciaraika@hotmail.com. ORCID iD: https://orcid.org/0000-0003-3396-3236. 
a methodological instrument for the collection and registration of the collected data. As an analytical basis, we had the Meaning Core. The result showed that teacher Vargas exalts creativity to circumvent the imperative contingencies of society, which disregards the particularities of PAEE students, and the means of access and permanence at school. We conclude that teacher Vargas, mediated by the experience with these included students, transformed his thinking, his feeling and his actions towards inclusive education.

Keywords:

Special and inclusive education. High school. Public grandparent students of special education.

\section{Estrategias de enseñanza y aprendizaje para la inclusión de estu- diantes que son el público objetivo de la educación especial en la escuela secundaria}

\section{Resumen:}

Las discusiones sobre la inclusión de los estudiantes en el público objetivo de la educación especial-PAEE impregna los diferentes sectores de la sociedad especialmente el ámbito académico. En este intento, el presente informe de investigación es un extracto de la tesis doctoral que se llevó a cabo en 2016, por la UFPI, y su objetivo general: analizar los significados de un docente de secundaria sobre la inclusión de estudiantes destinatarios de educación especial-PAEE. Es una investigación cualitativa, con enfoque en Psicología Socio histórica. El método utilizado fue el Materialismo Histórico Dialéctico. La entrevista fue elegida como instrumento metodológico para la recolección y registro de los datos recolectados. Como base analítica, teníamos el Núcleo de Significado. El resultado mostró que Vargas exalta la creatividad para sortear las contingencias imperativas de la sociedad, que desconoce las particularidades de los estudiantes de PAEE, y los medios de acceso y permanencia en la escuela. Concluimos que Vargas, mediado por la experiencia con estos estudiantes incluidos, transformó su pensamiento, su sentimiento y sus acciones hacia la educación inclusiva.

Palabras clave:

Educación especial e inclusiva. Escuela secundaria. Alumnos públicos de educación especial abuelos.

\section{Notas introdutórias sobre a educação especial e inclusiva}

Ao discutir-se sobre o processo de escolarização de alunos público-alvo da educação especial, entende-se que a inclusão escolar desses alunos rege a filosofia dos direitos iguais para todos os cidadãos, de não se aceitar a exclusão, a segregação ou quaisquer outras formas que os discrimine. Deve-se objetivar uma sociedade inclusiva, um sistema educacional inclusivo, tendo por base a igualdade de oportunidades para todas as pessoas que dela fazem parte.

A realização deste relato de pesquisa surgiu por meio da vivência profissional da pesquisadora, que a motivou para a investigação e análise dos significados e os sentidos constituídos por professores de ensino médio acerca da inclusão de alunos público-alvo da educação especial. Ao investigar este objeto de estudo, teve-se oportunidade de assimilar as significações de professores do ensino médio sobre educação inclusiva, assim como acerca da atividade de ensino-aprendizagem que desenvolvem com alunos PAEE, bem como suas as motivações para o desenvolvimento dessa atividade.

Com este intento, e diante da necessidade de analisar as significações de professores do ensino médio acerca da inclusão de alunos público-alvo da educação especial-PAEE, ressalta-se que 
a prática pedagógica desenvolvida pelo professor na educação, sobretudo na educação especial e inclusiva, tem relação com as condições objetivas e subjetivas que envolvem a atividade de docência. Assim, entende-se que as reflexões acerca das práticas pedagógicas inclusivas não são fáceis de serem objetivadas, por se tratarem de temática que evoca diferentes interpretações, bem como diante da realidade educacional para o processo de escolarização de alunos PAEE nas instituições escolares que não apresentam estruturas materiais e humanas que possibilitem a inclusão, com qualidade.

Destarte, desvela-se que esse grupo especial de educandos passou, e ainda passa, por processos de exclusão e de inclusão: social e educacional. Nesse contexto, analisa-se que as diversas produções culturais que surgiram acerca da inclusão dos alunos PAEE emergiram de reflexões e análises críticas contrárias à exclusão, de ações de negação de que a deficiência se torna uma alcunha que exclui o ser humano do direito de ser humano, de ser um cidadão, de ter o direito de viver e sobreviver nessa sociedade perversa, capitalista.

Na compreensão da unidade dialética exclusão e inclusão que permeia o legado histórico-cultural dos alunos público-alvo da educação especial, pode-se analisar os significados e os sentidos que foram se construindo quanto à transformação da sociedade, que ora considerava-os nulos socialmente e que hoje em dia lhes garante direitos sociais.

Ao refletir acerca da característica da exclusão pelas quais as pessoas PAEE passaram, destaca-se que essa característica, ainda se apresenta fortemente na atualidade. Infere-se que o impacto da exclusão, da não aceitação de convívio com a diversidade humana, com os alunos PAEE acarreta consequências como:

A sociedade perde por não ter a oportunidade e a possibilidade de apreender uma significativa parcela de seus elementos constitutivos, representados pelos 'diferentes' segregados. Com isso, todos perdemos em consciência, em comportamento e, consequentemente, em possibilidades de transformação. (ARANHA, 1995, p. 70),

Depreende-se, com o que afirma a autora, que a sociedade atual, imersa em diversidades humanas, deve possibilitar condições favoráveis de convivência com as diferentes pessoas, aceitando-as nas suas características físicas, comportamentais, bem como culturais.

Discute-se o desenvolvimento dos significados da educação especial à educação inclusiva, objetivados por estudiosos brasileiros nas produções do campo da pesquisa e da teoria educacional. Para isso, teve-se como referência autores como Mazzotta (2005), Jannuzzi (2006), Silva e Facion (2012), Dellani e Moraes (2012) e Glat (2009) que encampam a discussão da educação especial e inclusiva e que endossam as discussões que envolvem desde o período da antiguidade até os dias atuais.

Com base nas análises interpretativas dos contextos históricos acerca da educação de alunos com deficiências, encontra-se nos estudos de Mazzotta (2005) a compreensão de que as significações sociais foram mediadas por preconceitos diante dos aspectos físicos, cognitivos e comportamentais das pessoas com deficiência. Preconceitos oriundos de tradições religiosas, que defendiam a deficiência como um tipo de impureza da alma, excluindo as pessoas acometidas de algum tipo de deficiência do convívio social.

Os enfoques na educação especial, antes da década de 1970, tinham como referência a deficiência da pessoa, pois se compreendia que "[...] o que faltava a este alunado [da educação especial] quanto aos aspectos fisiológicos, neurológicos, psicológicos etc. em relação ao considerado normal [...] era o que o classificava como deficiente, como anormal" (JANNUZZI, 2006, p. 171). O padrão para fazer parte da educação especial era o de ser diferente de quem era considerado normal.

A partir da década de 1980, para Silva e Facion (2012), os alunos PAEE começaram a ter acesso à escola regular, pois se pôde conhecer um maior número de alunos com deficiência frequentando 
as escolas regulares, mesmo que em meio turno. Para os autores, desenvolveu-se, nessa década, o contexto educacional inclusivo, pois:

A escola inclusiva procura valorizar a diversidade existente no alunado inerente à comunidade humana, ao mesmo tempo em que busca repensar categorias, representações e determinados rótulos que enfatizam os déficits em detrimento das potencialidades dos educandos. (SILVA; FACION, 2012, p. 182).

Com possibilidades para que o aluno PAEE tenha suas limitações e suas potencialidades reconhecidas, Silva e Facion (2012) relatam que a inclusão desses alunos na escola regular favorece a aprendizagem e o desenvolvimento deles, pois não se aceita a sua exclusão e a sua segregação. Esses autores significam que a educação inclusiva consiste em um movimento educacional que respeita e valoriza as particularidades de cada indivíduo, com e sem deficiência, em que a inclusão é o lema social.

Exaltando a importância da escola inclusiva para os alunos público-alvo da educação especial salienta-se que, por meio de ambientes inclusivos, se torna possível que esses alunos tenham acesso a aprendizagens e desenvolvimentos comuns a todas as pessoas, bem como viabiliza as relações sociais que instigam a compreensão do ser diferente em uma sociedade classista. Incluir e conviver com os alunos PAEE desmitifica pré-conceitos sobre questões de (im)possibilidades que esses alunos podem realizar socialmente e academicamente, como assevera Bungenstab (2021, p. 7), toda pessoa deve ser compreendida como "[..] um ser singular que tem sua história e sua forma particular de enxergar o mundo e dar sentido a ele, bem como, também, é um ser social que ocupa um determinado lugar na sociedade".

A fim de ancorar a empiria desenvolvida neste relato de pesquisa, foi que se resgataram as contribuições teóricas sobre o cenário da literatura nacional evidenciando aspectos sociais e educacionais do surgimento da educação especial à inclusiva. Com este exposto, destaca-se que a escola Centro de Ensino Médio de Tempo Integral (CEMTI) Projetando a Educação ${ }^{2}$ foi selecionada como espaço educacional para realização deste estudo, pois trabalha com a dimensão pedagógica, política, social, cultural, administrativa e humana de seus alunos, tendo como eixo central a dimensão político-pedagógica e a inclusão social. A professora participante da pesquisa, que foi denominada de Vargas ${ }^{3}$, ministra aulas de História nessa escola, trabalhando na rede pública estadual de ensino há quinze anos.

\section{Tecendo caminhos metodológicos}

Optou-se pela pesquisa qualitativa diante das possibilidades que ela apresenta na apreensão das significações constituídas pela participante da pesquisa, acerca da educação inclusiva. Como método, fundamentou-se no Materialismo Histórico Dialético, que possibilita ao pesquisador “[...] o conhecimento real por meio da análise crítica do material concreto-real, um método de análise concreta do objeto concreto, dos fatores reais" (KOPIN, 1978, p. 78). Os instrumentos e as técnicas para produção e registro dos dados utilizados foram as entrevistas: narrativa e reflexiva. E, para análise e interpretação dos fatos e dos acontecimentos narrados pela professora, fez-se uso da proposta dos "núcleos de significação" (AGUIAR; OZELLA, 2006; AGUIAR; SOARES; MACHADO, 2015).

20 nome da escola é fictício, para zelar pela identidade da instituição escolar.

3 Nome fictício denominado pela pesquisadora autorizado pela professora participante da pesquisa. 
Neste relato de pesquisa, trabalhou-se com a abordagem da Psicologia Sócio-Histórica (VYGOTSKI, 2009; 2010), que possibilitou compreender acerca da constituição do ser professor, da subjetividade produzida nas relações com outras pessoas e nas condições objetivas vivenciadas por ele. A técnica utilizada para o registro de dados foi a entrevista, que, de acordo com Severino (2007, p. 124), representa o registro de informações “[...] sobre um determinado assunto, diretamente solicitado aos sujeitos pesquisados. [...]. O pesquisador visa apreender o que os sujeitos pensam, sabem, representam e argumentam."

Pautados por esses aportes metodológicos, informa-se que o lócus da pesquisa foi o CEMTI Projetando a Educação, que se apresenta como referência e vem se destacando junto à comunidade do bairro em que está inserido. A referida escola tem participado do Prêmio Gestão Escolar ${ }^{4}$ e tem sido classificada, desde 2011 aos dias atuais, entre as escolas da Federação que concorrem à premiação, demonstrando que realiza atividades educativas que objetivam melhorar a qualidade do ensino oferecido a seus alunos. Conforme narrou a professora Vargas (LIMA, 2016, s. p.) na entrevista narrativa:

Você sabia que teve um aluno que foi assassinado dentro dessa escola? Ah... Em 1998, na feira de Ciências. Essa escola aqui já foi tida como a pior escola do bairro. Você consegue ver isso aqui hoje? [...]. A escola problema, dentro da área do bairro, poderia ser considerada o CEMTI Projetando a Educação! Você consegue ver isso [violência] hoje? Quantas carteiras nós temos quebradas? Nenhuma. Quantas paredes pichadas? Nenhuma. Por quê? Porque nós começamos um trabalho de formiga, trouxemos o cultural, começamos a trazer projetos de Arte, começamos a trabalhar com projetos.

Realizou-se entrevista com a professora Vargas, que teve como objetivo conhecer acerca da atividade profissional que realizava, para desvelar como se constituiu como professora e sua relação com a educação inclusiva de alunos público-alvo da educação especial. A entrevista foi realizada na escola em que trabalhava, em dia e horário agendado por ela.

Com a narrativa da professora, conseguiu-se identificar, nos trechos revelados, referências a atividades de ensino-aprendizagem realizadas em sala de aula que evidenciaram não segregar, excluir ou discriminar os alunos PAEE em sala de aula.

\section{(Com)provando os fatos}

Para a análise e a discussão dos registros dos dados da participante da pesquisa, seguiu-se a proposta dos "núcleos de significação", segundo o que apresentam Aguiar e Ozella (2013). Esses autores analisam que, em relação à aplicabilidade dos núcleos de significação, o pesquisador deve atentar cuidadosamente ao material empírico produzido, pois neste, inicialmente, apreendem-se os significados. Os sentidos a serem apreendidos são mais complexos, necessitam ser evidenciados nas expressões mais contraditórias apresentadas pelas pessoas.

Essa proposta analítica consiste em vários momentos de imersão do pesquisador no material empírico produzido, de modo a se aproximar das zonas de sentido do participante da pesquisa. Esses momentos são sistematizados em três etapas: os pré-indicadores, os indicadores e os núcleos de significação. Os pré-indicadores são as palavras, frases ou expressões em negrito que se destacam e carregam sentimentos, emoções da totalidade do ser a professora Vargas, que analisamos no corpus empírico nas narrativas apresentadas por ela. Como direcionam Aguiar e Ozella (2006, p. 230) “Um

4 Ver informações sobre o Prêmio Gestão Escolar. Disponível em: <http://undime-sc.org.br/wp-content/uploads/2015/07/Regulamento-Pr\%C3\%AAmio-Gest\%C3\%A3o-Escolar.pdf>. Acesso em: 04 jan. 2016. 
critério básico para filtrar esses pré-indicadores é verificar sua importância para a compreensão do objetivo da investigação". Os indicadores, que consistem no processo de aglutinação dos pré-indicadores, constituem-se pela similaridade, pela complementaridade ou pela contraposição, de modo que nos levem à menor diversidade das expressões destacadas como pré-indicadores. Identificados os pré-indicadores e indicadores chega-se à etapa dos núcleos de significação, que possibilitam a apreensão dos sentidos constituídos pelas narrativas dos participantes da pesquisa. Esta última etapa representa as zonas de sentido objetivadas na pesquisa.

Como exemplo desse processo analítico, apresenta-se o segundo núcleo, intitulado: $\mathrm{O}$ “jogo de cintura" da professora para incluir alunos PAEE: enfrentamento das condições objetivas e subjetivas como possibilidade para a educação inclusiva, que foi constituído a partir da articulação de cinco indicadores ${ }^{5}$ que exprimem os diferentes sentidos constituídos por Vargas acerca da educação inclusiva. Essas múltiplas determinações, vivenciadas por ela, revelam o seu modo de pensar, de sentir e de agir como professora de alunos PAEE diante do contexto da educação inclusiva.

Dentre as diversas análises desenvolvidas nesse núcleo, apresenta-se as narrativas produzidas por Vargas que foram especificadas no segundo indicador intitulado: $\mathrm{O}$ "jogo de cintura" da professora mediando a criação de estratégias de ensino e aprendizagem que favorecem à inclusão de alunos PAEE nas tarefas escolares, a saber:

[...] eu resolvi utilizar uma hora do meu horário, chamando eles [os alunos especiais], para tentar ajudar na minha disciplina. Como a disciplina é História, eu tinha falado da pré-história e ia entrar no Egito, começava a colocar nomes para eles e imagens e eles começavam a me dar sinais é... do que seria isso dentro da linguagem de sinais, da Libras. Eu apontava para a imagem do Egito... eles faziam sinais de acordo com a linguagem de sinais e, nisso, eu fui aprendendo Libras aos poucos, a ponto de, num certo período, sair do Ensino Regular e ficar no Atendimento Educacional Especializado (AEE). [...]. (LIMA, 2016, p. 108, grifos nossos).

Vargas sente-se desafiada diante da necessidade de realizar sua atividade profissional com alunos PAEE. Após identificar que em sua sala de aula tinha esses discentes e diante das condições objetivas que a educação inclusiva se apresentava no cenário educacional, a referida professora tenta fazer com que esses alunos consigam apropriar-se das atividades de ensino-aprendizagem realizadas na disciplina de História, ao afirmar: "[...] resolvi utilizar uma hora do meu horário".

Nessa relação de ensino-aprendizagem, Vargas produz como sentidos o fato de que esses alunos só apreendem se não forem vistos apenas como deficientes, apenas nos aspectos orgânicos. Tal percepção produzida por Vargas nos leva à concepção de Freire (2011), que esclarece que quem ensina aprende e quem aprende também ensina.

Vargas, ao ensinar os alunos PAEE, em seu modo de agir como professora de educação inclusiva, afirma: (LIMA, 2016, p. 191, grifos nossos) "[...] senti necessidade de fazer cursos de capacitação"; e se satisfez "[...] realizando curso de formação contínua em Libras". Entretanto, novas necessidades foram surgindo diante da atividade de ensino e aprendizagem com esses alunos. Embasa-se nas palavras de Leontiev (1978), para esclarecer que, nessa atividade realizada por Vargas, os motivos que a levaram a essa realização, da atividade escolar com os alunos PAEE, coincidem com os objetivos da atividade docente, que é o de possibilitar que os alunos se apropriem da cultura sistematizada, a qual é considerada como essencial para que os discentes se tornem pessoas autônomas e participativas, para agirem na sociedade em que vivem.

5 1. Estratégias de ensino-aprendizagem que favorecem a inclusão de alunos com NEES tarefas escolares; 2 . Os projetos como estratégias potencializadoras para a inclusão dos alunos com PAEE nas tarefas escolares; 3 . A professora passa a ter uma visão diferenciada em relação aos alunos com PAEE por meio de sua experiência com a educação inclusiva; 4. Atividades com projetos e cursos mediando o ensino-aprendizagem dos conteúdos escolares e superação de problemas socioeconômicos; 5 . A professora chocando alunos com o assunto da matéria e tornando-os protagonistas do seu aprendizado. 
Dessa forma, infere-se que o sentido produzido por Vargas acerca da atividade de ensino e aprendizagem de alunos PAEE na escola regular se confirma com as palavras de Capellini e Santos (2005, p. 79), que discutem sobre os desafios de professores com a educação inclusiva, o que compreende que incluir alunos PAEE em escolas de ensino regular não "[...] consiste apenas no acesso à matrícula na escola regular, mas na busca por estratégias pedagógicas que os possibilitem ao domínio dos conteúdos formais, em conformidade com as suas capacidades de aprendizagem e de desenvolvimento".

Pode-se constatar, com as análises apreendidas das narrativas de Vargas, que a realização de atividades inclusivas em escolas de ensino médio que propiciem a participação e envolvimento de alunos PAEE, apresentam diferentes facetas, dentre elas, aquelas que se considera negativas: as condições objetivas apresentadas pelo cenário educacional de precarização do trabalho docente, desvalorização salarial, falta de estruturas educacionais para o desenvolvimento de atividades inclusivas com alunos PAEE na escola regular, dentre outras; e, aquelas que podemos considerar positivas, como a evidenciada no relato em tela, em que, ao identificar o aluno PAEE em sala de aula, o professor poderá ser afetado positivamente para atividade docente com esses alunos e dar novas significações à educação inclusiva, usando da criatividade para a realização de atividades do currículo para que esses alunos não sejam excluídos, segregados ou mesmo passíveis de bullying pelos seus pares.

Constata-se, com o exposto, que incluir alunos PAEE na escola de ensino médio requer que os profissionais da educação reflitam sobre sua prática pedagógica, transformando o seu pensar, seu agir e seu sentir diante do atual cenário educacional: da educação inclusiva. E que, mesmo diante das disparidades sociais, em que uns são mais privilegiados do que outros, possam-se resgatar, por meio da leitura deste estudo, as experiências desenvolvidas por Vargas que usou de sua criatividade para driblar as contingências imperativas da sociedade, que desconsidera as particularidades dos alunos PAEE e os incluiu nas atividades pedagógicas que realizou na escola, na sala de aula e em suas aulas de História.

\section{Considerações reflexivas}

Entende-se que o relato de pesquisa ora descrito, converge para que os profissionais da educação, e aqueles que têm interesse pela temática, possam refletir sobre a atividade profissional que desenvolvem no atual cenário educacional, de inclusão escolar de alunos PAEE, e sejam motivados a repensar e transformar seu fazer docente, driblando as intempéries determinantes das condições objetivas e subjetivas da sociedade capitalista, e possam usar de sua criatividade para incluir, com qualidade, esses discentes. E, nesse modo de agir, considere as necessidades específicas para a aprendizagem de cada aluno, para que possam sentir-se incluídos na escola e no processo de apropriação dos conteúdos culturalmente elaborados.

Nessa linha de pensamento, ressalta-se que a atividade docente como alunos PAEE mediada pela educação inclusiva, permite aos professores uma revisão dos serviços de educação especial e a construção de novas significações dos e nos sistemas de ensino. (MACHADO, 2009). Nesta compreensão, os professores que já tiveram oportunidade de ter em sala de aula alunos PAEE, bem como aqueles que ainda não tiveram essa oportunidade, mas que entendem que a inclusão escolar já é fato, que não se aceita retrocesso do processo inclusivo, devem refletir sobre o paradigma da educação inclusiva. Paradigma que se apresenta como possibilidades para a transformação da atividade de docência, com capacidade de refletir criticamente sobre a realidade educacional, e, intervir nas condições objetivas e subjetivas que se encontram profissionalmente para minimizarem as barreiras que impedem que a educação inclusiva se realize com qualidade. 
Compreende-se que, investigar um fenômeno social, neste caso as significações docentes, possibilita o envolvimento com a lógica dialética, especialmente por propiciar que os professores pesquisadores saiam de sua zona de conforto e sejam levados a novos pensamentos, novas reflexões e novas formas de entender e de explicar as relações de inclusão e exclusão, homem e mundo.

\section{Referências}

AGUIAR, Wanda Maria Junqueira de; OZELLA, Sérgio. Núcleos de Significação como instrumento para a apreensão da constituição dos sentidos. Revista Psicologia Ciência e Profissão, ano 26, n. 2, p. 222-246, 2006.

AGUIAR, Wanda Maria Junqueira de; SOARES, Júlio Ribeiro; MACHADO, Virgínia Campos. Núcleos de Significação: uma proposta histórico-dialética de apreensão das significações. Cadernos de pesquisa, v. 45, n. 155, p. 56-75, jan./mar, 2015.

ARANHA, Maria Salete Fábio. Integração Social do Deficiente: Análise Conceitual e Metodológica. Temas em Psicologia, n. 2, p. 63- 70, 1995

BUNGENSTAB, Gabriel Carvalho. Quem são os jovens do ensino médio? Cadernos do Aplicação, v. 34, n. 1, p. 13-46, jan./ jun. 2021.

CAPELLINI, Vera Lucia Messias Fialho; SANTOS, Marisa Aparecida Pereira. Inclusão na universidade: desafios para os novos educadores e para os atuais formadores. Revista do VII Congresso Estadual Paulista sobre Formação de Educadores, p. 72-81. Disponível em: http://www.unesp.br/prograd/e-book\%20viii\%20cepfe/pagina02.htm. Acesso em: 26 jun. 2013.

DELLANI, Marcos Paulo; MORAES, Deisy Nara Machado de. Inclusão: caminhos, encontros e descobertas. REI: Revista de Educação do IDEAU, Caxias do Sul, v. 7, n. 15, jun. 2012.

FREIRE, Paulo. Pedagogia do Oprimido. 43. ed. Rio de Janeiro: Paz e Terra, 2011.

GLAT, Rosana. (org.). Educação Inclusiva: cultura e cotidiano escolar. Rio de Janeiro: 7 letras, 2009.

JANNUZZI, Gilberto de Martino. A educação do deficiente no Brasil: dos primórdios ao início do século XXI. Campinas: Autores Associados, 2006.

KOPNIN, Pável Vasilyevich. A dialética como lógica e teoria do conhecimento. Rio de Janeiro: Civilização Brasileira, 1978.

LEONTIEV, Alexei Nikolaevich. Actividad, Conciencia y Personalidad. Buenos Aires: Ciências Del Hombre, 1978.

LIMA, Marcia Raika e Silva. Meu mundo caiu! As significações de uma professora de Ensino Médio acerca da atividade de ensino aprendizagem de alunos com Necessidades Educativas Especiais. 2016. 235 f. Tese (Doutorado em Educação)

- Universidade Federal do Piauí, Teresina, 2016.

MAZZOTTA, Marcos José Silveira. Educação Especial no Brasil: história e políticas públicas. 5. ed. São Paulo: Cortez, 2005.

SEVERINO, Antônio Joaquim. Metodologia do trabalho científico. 23. ed. rev e atualizada. São Paulo: Cortez, 2007.

SILVA, Maria de Fátima Minetto Caldeira; FACION, José Raimundo. Perspectiva da inclusão escolar e sua efetivação. In: FACION, José Raimundo (org.). Inclusão escolar e suas implicações. Curitiba: Intersaberes, 2012. p. 175-205.

VYGOTSKI, Lev Semenovich. A construção do pensamento e da linguagem. São Paulo: Martins Fontes, 2009.

VYGOTSKI, Lev Semenovich. Pensamento e linguagem. 4. ed. São Paulo: Martins Fontes, 2010.

Data de submissão: 15/05/2021

Data de aceite: $23 / 06 / 2021$ 